\title{
Using environmental niche modelling to investigate abiotic predictors of crocodilian attacks on people
}

\author{
George Powell, Thomas M. M. Versluys, Jessica J. Williams \\ SONIA TIEDT and SIMON POOLEY
}

\begin{abstract}
Crocodilians are distributed widely through the tropics and subtropics, and several species pose a substantial threat to human life. This has important implications for human safety and crocodilian conservation. Understanding the drivers of crocodilian attacks on people could help minimize future attacks and inform conflict management. Crocodilian attacks follow a seasonal pattern in many regions, but there has been limited analysis of the relationship between attack occurrence and fine-scale contemporaneous environmental conditions. We use methods from environmental niche modelling to explore the relationships between attacks on people and abiotic predictors at a daily temporal resolution for the Nile crocodile Crocodylus niloticus in South Africa and Eswatini (formerly Swaziland), and the American alligator Alligator mississippiensis in Florida, USA. Our results indicate that ambient daily temperature is the most important abiotic temporal predictor of attack occurrence for both species, with attack likelihood increasing markedly when mean daily temperatures exceed $18{ }^{\circ} \mathrm{C}$ and peaking at $28^{\circ} \mathrm{C}$. It is likely that this relationship is explained partially by human propensity to spend time in and around water in warmer weather but also by the effect of temperature on crocodilian hunting behaviour and physiology, especially the ability to digest food. We discuss the potential of our findings to contribute to the management of crocodilians, with benefits for both human safety and conservation, and the application of environmental niche modelling for understanding human-wildlife conflicts involving both ectotherms and endotherms.
\end{abstract}

George Powell* Big Data Institute, Li Ka Shing Centre for Health Information and Discovery, Nuffield Department of Medicine, University of Oxford, Oxford, UK

Thomas M. M. Versluys* (Corresponding author) Department of Life Sciences, Silwood Park Campus, Imperial College London, Ascot, UK

E-mail tmv3318@ic.ac.uk

Jessica J. Williams (D orcid.org/0000-0002-8275-7597) Department of Genetics, Evolution and Environment, Centre for Biodiversity and Environment Research, University College London, London, UK

Sonia TiedT School of Public Health, Imperial College London, London, UK

Simon Pooley (D orcid.org/0000-0002-0260-6159) Department of Geography, Birkbeck University of London, London, UK, Department of Zoology, WildCRU, University of Oxford, Oxford, UK, and School of Life Sciences, University of KwaZulu-Natal, Pietermaritzburg, South Africa

${ }^{*}$ Contributed equally

Received 12 March 2019. Revision requested 9 May 2019.

Accepted 4 June 2019. First published online 15 June 2020.
Keywords Conservation management, crocodilian conservation, environmental niche modelling, human-crocodilian conflict, human-wildlife conflict, spatio-temporal modelling Supplementary material for this article is available at doi.org/ 10.1017/Soo30605319000681

\section{Introduction}

T anaging conflicts involving wildlife is a serious challenge globally, especially when the conflicts pose a direct threat to human life (Woodroffe et al., 2005). Over large regions of the tropics and subtropics crocodilians are responsible for more attacks on people per year than any other large carnivore, with incidents reported for 65 countries (CrocBITE, 2018). They also attack domestic animals such as livestock and dogs, damage fishing nets, burrow through earthen dam walls, and cause general disruption to movement and livelihoods by restricting the use of waterways that are required for travel, fishing and household chores (Aust et al., 2009; Lamarque et al., 2009).

Successfully mitigating harmful human-crocodilian interactions has important implications not just for human safety but also for conservation. Negative impacts on people have resulted in retaliatory killings and exacerbated issues such as overharvesting and habitat destruction (Fukuda et al., 2015), which can have wider consequences for ecosystems. As the apex predator of the aquatic environments they inhabit, and as carnivores with varied diets, crocodilians play a key role in local food webs, affecting abundance and behaviour of prey species in ways that can influence the function and community structure of ecosystems (van der Ploeg et al., 2011). They also transport nutrients from land to water by preying on land animals, or across ecosystems, as in cases where they travel to feed in estuarine areas before returning to freshwater areas. Crocodilians are also ecosystem engineers, modifying their environment by digging dens, holes and tunnels, and creating nest sites. Alligator holes, for instance, retain water during dry seasons and serve as refuges for other aquatic species (Britton, 2009).

Understanding the drivers of crocodilian attacks can help minimize future incidents and inform conflict management. Previous analysis of crocodilian attack patterns has focused on identifying high-risk human demographics and behaviours; there has been limited analysis of potential abiotic 
environmental predictors of attack patterns, such as temperature and rainfall (Fukuda et al., 2015; Brien et al., 2017; Das \& Jana, 2017). There are, however, strong theoretical grounds for the importance of abiotic conditions because temperature constrains crocodilian hunting behaviour via effects on ectotherm physiology, especially metabolic function (Hutton, 1987; Lance, 2003; Seebacher \& Franklin, 2005). Similarly, people's propensity to expose themselves to crocodilian-inhabited waterways is probably correlated with environmental conditions. Accordingly, despite crocodilian attacks occurring year-round in many tropical regions (e.g. India and Bangladesh), documented attack patterns are highly seasonal across Australia (Brien et al., 2017) and are correlated with mean monthly rainfall and temperature in South Africa, Eswatini and the southern USA (Woodward et al., 2014; Pooley, 2015). To date, studies have only explored the contribution of abiotic factors at a coarse temporal and spatial resolution. In particular, they have exclusively used average monthly or seasonal data, which do not capture the impact of climatic changes across days. Furthermore, these data have been used to represent regional environmental conditions, but have typically been sourced from single weather stations, limiting the ability to capture variation across space.

Here, we use environmental niche modelling methods to examine the relationships between abiotic and biotic variables and the occurrence of crocodilian attacks on people at a greater spatial and temporal resolution than in previous studies. Environmental niche modelling describes methods for inferring the occurrence of biological phenomena in environmentally heterogeneous areas and has previously been utilized to analyse human conflict with jaguars in Brazil and Mexico (Zarco-González et al., 2013; Carvalho et al., 2015), wolves in Iran (Behdarvand et al., 2014), leopards in Pakistan (Kabir et al., 2014) and monkeys in India (Beisner et al., 2015). Crocodilian attacks can theoretically be thought of as an entity that can only occupy a specific environmental niche defined by particular biophysical limits; thus, it is possible to use environmental niche modelling to illustrate the likelihood of attack occurrence over time in a heterogeneous environment.

We focus on two species of crocodilian that come into regular conflict with humans: the East African Nile crocodile Crocodylus niloticus in South Africa and Eswatini, which is estimated to be responsible for more human fatalities per year than all other crocodilians combined (Dunham et al., 2010; Wallace et al., 2011), and the American alligator in Florida Alligator mississippiensis, which is one of few indigenous predators that poses a substantial threat to human life in the southern USA (Woodward et al., 2014). We discuss the potential of our findings to contribute to the management of crocodilians, especially in subtropical and temperate areas where climatic conditions are similar to those in our study regions. We also highlight the benefits for human safety and conservation arising from this study, as well as the potential application of environmental niche modelling to the analysis of conflict with other species, both ectothermic and endothermic.

\section{Methods}

\section{Attack and biophysical data}

Information on attacks by Nile crocodiles in South Africa and Eswatini (1951-2016) was obtained from archival searches including the personal archive of Tony (A.C.) Pooley (conservation warden responsible for monitoring crocodile attacks in Natal Province, 1966-1984, who was active in investigations until 2003), attack records kept at the St Lucia Crocodile Centre, Mtubatuba, South Africa, provincial and national newspapers (print and online) in KwaZuluNatal and South Africa, and the Times of Swaziland archive in Mbabane, Eswatini. Online searches used the search term 'crocodile' paired with 'attack', 'bite' or 'victim', in English and Afrikaans. Information on American alligator attacks in Florida (1971-2014) was provided by the Fish \& Wildlife Conservation Commission (FWC, 2016). Incidents involving a bite were reported to the Commission by telephone, by victims or their families, medical caregivers, or law enforcement agencies. In most instances post 1970, the Commission's law enforcement officers conducted investigations and interviewed victims and witnesses. Attacks by crocodilians were excluded if they were not witnessed or lacked forensic support, if spatial or temporal data were lacking, or if they were classified as provoked.

The attack records had different spatial resolutions: geographical coordinates were available for the Nile crocodile attacks (Fig. 1), whereas for the American alligator attacks the Florida county in which the attack occurred was recorded (Fig. 2). ArcGIS 10.4 (Esri, Redlands, USA) was used to ensure Nile crocodile attack coordinates fell within the IUCN predicted distribution of Nile crocodiles in South Africa and Eswatini (IUCN, 1996), and within $1 \mathrm{~km}$ of a waterbody (Defence Mapping Agency, 1992).

We compiled a dataset of biotic and abiotic environmental predictors that could be spatially and temporally linked to attacks. The climatic variables were mean daily temperature and rainfall, and mean monthly rainfall (20-year means). Historical data were not available for crocodile and alligator population densities across the study regions, but human population density was included as a biotic predictor because the majority of attacks in our study areas were on local residents (Woodward et al., 2014; Pooley, 2015). Year and month were included, to account for temporal trends.

Daily rainfall and minimum and maximum temperature data were obtained from Young et al. (2017). We gathered 


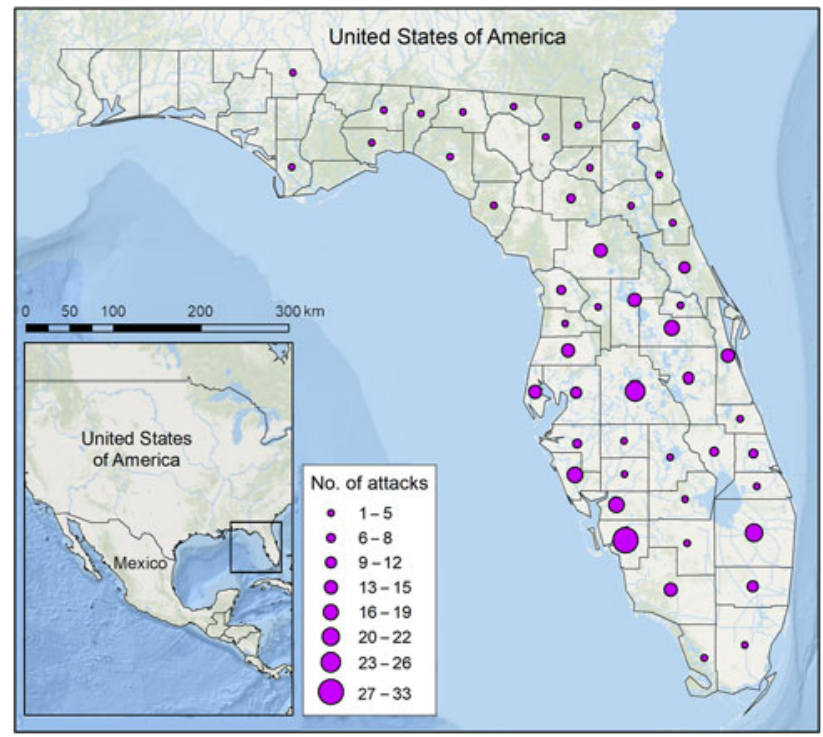

FIG. 1 The number of American alligator Alligator mississippiensis attacks (total =335) in each county in Florida, USA, during 1971-2014.

data from all weather stations within a $300 \mathrm{~km}$ perimeter of the distribution (IUCN, 1996) of Nile crocodiles in South Africa and Eswatini $(\mathrm{n}=514)$, and all stations within Florida $(n=1,131)$. To account for collinearity, mean temperature was calculated from minimum and maximum values. For the Nile crocodile dataset, missing temperature data were linearly interpolated when the gap between records did not exceed 3 days, increasing coverage by $9.99 \%$. Average monthly rainfall was calculated as means of all days within each month. Climatic variables were linked to each Nile crocodile attack record from the closest NOAA station. Temperature measurements were adjusted based on the difference between the attack elevation and station elevation (Fick \& Hijmans, 2017), according to the temperature lapse rate defined by the International Civil Aviation Organization (ICAO, 2017). Mean climatic values were calculated for each county in Florida from all encompassed stations and were linked to attack records according to date and county.

Human population density in South Africa was estimated for the magisterial district encompassing each attack from the closest of seven historical censuses (1951, 1960, 1970, 1980, 1991, 1996, 2001; digitized and geo-referenced by Giraut \& Vacchiani-Marcuzzo, 2009). The annual human population density of Eswatini was obtained from UN (2017). Florida county human population densities were estimated using contemporaneous data from the year of the attack provided by the Office of Economic and Demographic Research (OEDR, 2017). In addition, the total wetland area in each county, taken to be a measure of potential alligator habitat (and used when selecting background points, see below), was estimated from the National Wetlands Inventory (U.S. Fish \& Wildlife Service, 2017).

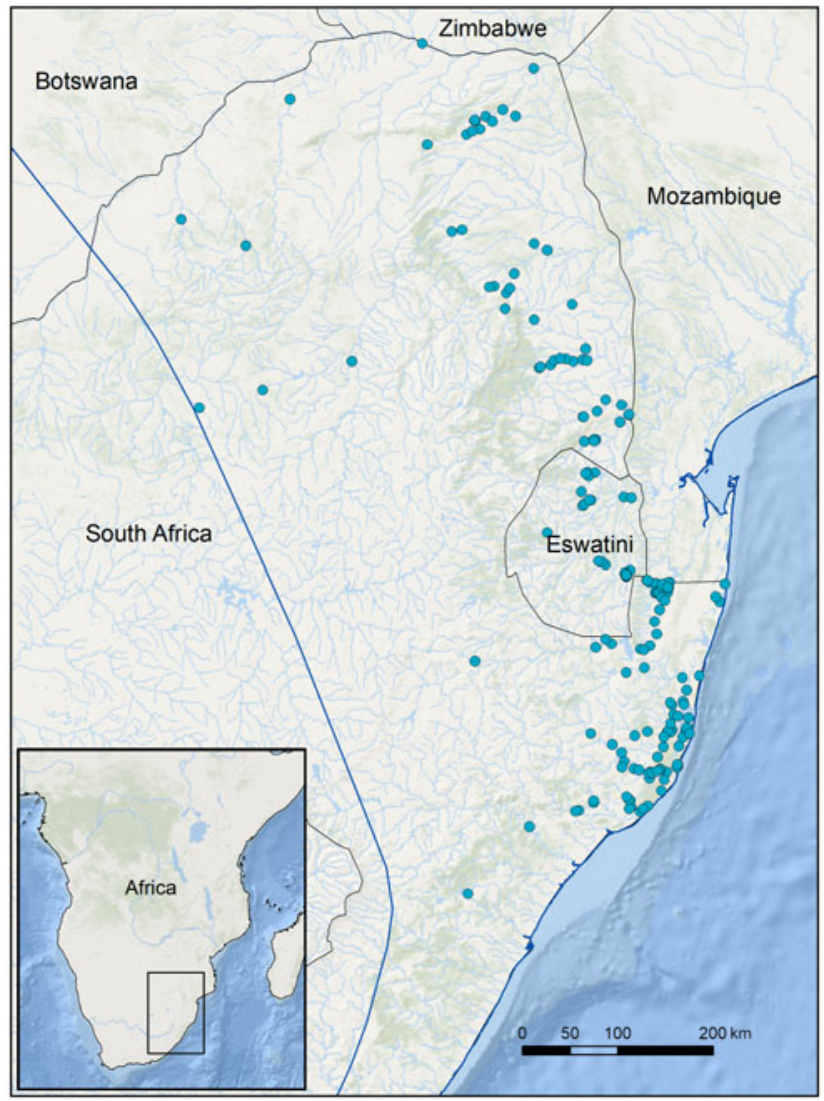

FIg. 2 The locations of Nile crocodile Crocodylus niloticus attacks $(n=188)$ in South Africa and Eswatini during 1951-2016; the line indicates the westernmost limit of the Nile crocodile's distribution (IUCN, 1996).

The final crocodile dataset comprised 188 attacks recorded in South Africa and Eswatini between September 1951 and December 2016. The final alligator dataset comprised 335 attacks recorded in Florida between September 1971 and December 2014. Both datasets included mean daily temperature and rainfall, mean monthly rainfall, human population density, month and year as variables for modelling.

\section{Background points}

Attack records constitute presence only data, and there is no reliable measure of human-crocodilian exposure to quantify when attacks did not occur. However, when absence data are not available, models can be used with background points that are randomly sampled to characterize the null distribution of each variable in the model (Elith et al., 2008; Barbet-Massin et al., 2012).

Background point sampling influences the results of environmental niche models (Barbet-Massin et al., 2012; Phillips et al., 2009). Therefore, we used two background sampling methods for each species to compare and assess 
the influence of background point sampling on the results (background sampling methods A and B). Each method was used to create datasets of 10,00o background points for Nile crocodiles and American alligators that could be sampled for model fitting. For method A we stratified background point sampling according to where attacks have been reported: 10,000 Nile crocodile attack coordinates were randomly sampled and randomly assigned dates between 1951 and 2016, and 10,000 American alligator background points were randomly sampled from Florida counties proportional to the number of reported attacks and randomly assigned dates between 1971 and 2014. For method B we sampled background points across the species' predicted ranges: 10,000 Nile crocodile background points were randomly selected as coordinates that fall on water bodies within the IUCN distribution of Nile crocodiles in South Africa and Eswatini, and 10,000 American alligator background points were sampled from all counties in Florida (Woodward et al., 2014). To make this method comparable between the species, the probability of a Florida county being sampled was proportional to its total wetland area (i.e. counties with more wetland area had a proportionally higher probability of selection). Covariates were linked to background points following the same process as for attack records.

\section{Model fitting}

Spearman's Rank correlation was calculated between all variables prior to model fitting (Supplementary Table 1). We first assessed attack seasonality for both species by calculating Spearman's Rank correlations between the total number of attacks per month, and mean monthly temperature and monthly rainfall, calculated using the background datasets. We analysed attack patterns at a finer spatial and temporal resolution using boosted regression trees, which were fit to express nonlinearities in the data (Elith et al., 2006).

We sampled background points from the background datasets following Barbet-Massin et al. (2012). Boosted regression trees had an equal ratio of background points to attacks, and were fit with 10 -fold cross validation, as recommended by Miller (2015), and model fit was evaluated as the mean area under curve of the receiver operating characteristics (ROC) plot. Boosted regression tree model parameters that maximized ROC were selected. Each tree had a learning rate of 0.005 , a tree complexity of 5 and a bag fraction of 0.5. The number of boosted trees varied for each model but were selected to minimize holdout deviance. Boosted regression tree model contribution was assessed based on the number of times the variable was selected for splitting, weighted by the squared improvement to the model as a result of each split, and averaged over all trees (Friedman \& Meulman, 2003). Background point sampling affects ROC and variable importance and therefore we used a bootstrapping technique in which each model was fit 100 times with independently sampled background points, and variable importance and ROC were measured across each iteration. All analyses were conducted in $R$ 3.4.3 (R Core Team, 2018) and boosted regression trees were fit using the $g b m$ 2.1.3 package (Ridgeway, 2010).

\section{Results}

Both species have a seasonal pattern of attack frequency (Fig. 3). There is a significant correlation between number of attacks and mean monthly temperature over the study period for alligators $(\omega(10)=0.95, \mathrm{P}<0.001)$ in Florida and crocodiles $(\rho(10)=0.98, \mathrm{P}<0.001)$ in South Africa and Eswatini, and a significant correlation between number of attacks and mean monthly rainfall for alligators $(\rho(10)=0.82, \mathrm{P}<0.001)$ and crocodiles $(\rho(10)=0.95$, $\mathrm{P}<0.001)$.

The crocodile boosted regression trees had a mean crossvalidation ROC value of $0.83 \pm \mathrm{SD} 0.02$ using background dataset $\mathrm{A}$, and $0.85 \pm \mathrm{SD} 0.01$ using background dataset $\mathrm{B}$. The alligator boosted regression trees had a mean crossvalidation ROC value of $0.69 \pm$ SD 0.02 using background dataset $A$, and $0.77 \pm S D 0.02$ using background dataset $B$.

With background point sampling stratified by attack locations (background dataset $\mathrm{A}$ ), mean daily temperature was the most important predictor of attack occurrence based on model contribution for both Nile crocodiles (41.16 \pm SD 3.73) and American alligators (42.97 $\pm \mathrm{SD} 4.16)$, and this was consistent for each model fitting iteration (Fig. 4). The distributions of model contribution overlap for daily rainfall, mean monthly rainfall, human population density, year and month for both species, highlighting the variability introduced by background sampling (Fig. 4). However, on average, the second and third most important predictors of Nile crocodile attack occurrence were human population density (17.86 \pm SD 2.58), and mean monthly rainfall (14.80 \pm 2.71$)$, and of American alligator attack occurrence, year $(14.87 \pm \mathrm{SD}$ 1.98) and human population density (11.90 \pm SD 1.95).

With background points sampled across the species' predicted ranges (background dataset B), mean daily temperature and human population density were the strongest predictors of attack occurrence. For American alligators, mean boosted regression tree contribution was $32.34 \pm \mathrm{SD}$ 3.42 and $34.85 \pm \mathrm{SD}_{3} .44$ for daily average temperature and human population density, respectively. For Nile crocodiles, mean boosted regression tree contribution was $49.42 \pm \mathrm{SD}_{3.83}$ and $16.93 \pm \mathrm{SD} 2.67$ for mean daily temperature and human population density, respectively. The relative increase in the strength of human population density as a predictor when background points are sampled across the species' predicted ranges (background dataset B) 
(a) American alligator

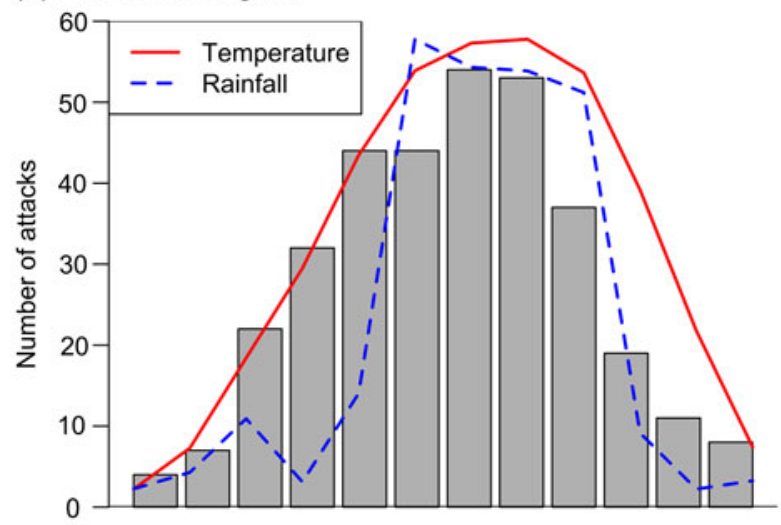

(b) Nile crocodile

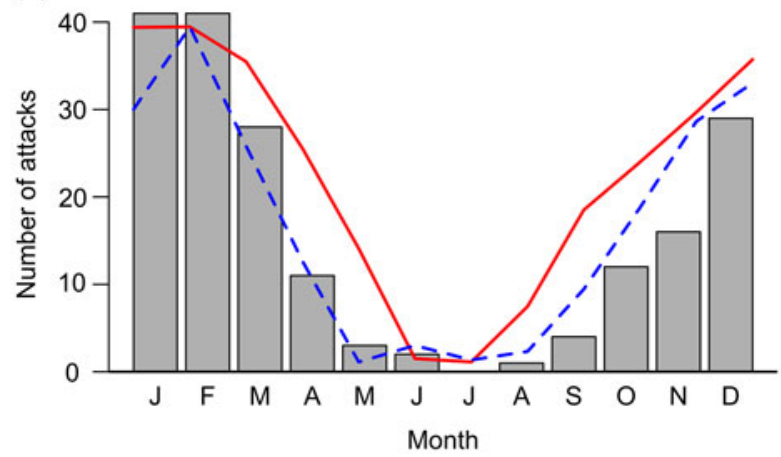

FIG. 3 Seasonal variations in the incidence of attacks by (a) American alligators in Florida during 1971-2014, and (b) Nile crocodiles in South Africa during 1951-2016, with mean monthly rainfall and temperature of background points $(n=10,000)$.

compared with when sampling is stratified by attack location (background dataset A) is probably the result of an increase in attack likelihood variance across space. This would increase the relative importance of the covariate that is the strongest spatial predictor. In our case, this is human population density, which varies greatly across state county and magisterial district. Human population density has a nonlinear relationship with attack occurrence across the predicted ranges of both species. This is probably a result of the patchy distribution of crocodilians and people, as attacks are heavily dependent on the relative local abundance of both and can only occur when there is exposure between the two. The lack of historical fine-scale human and crocodilian population density data, or other proxies for encounter rates between people and crocodilians, probably limits the accuracy of our models, and it is possible that the inclusion of further covariates would affect the relative importance of predictors.

Boosted regression trees indicate that the probability of attack occurrence increases for Nile crocodiles and American alligators as temperature increases. Boosted regression tree partial dependence plots highlight the relationship between mean daily temperature and attack likelihood after accounting for the average effects of all other variables

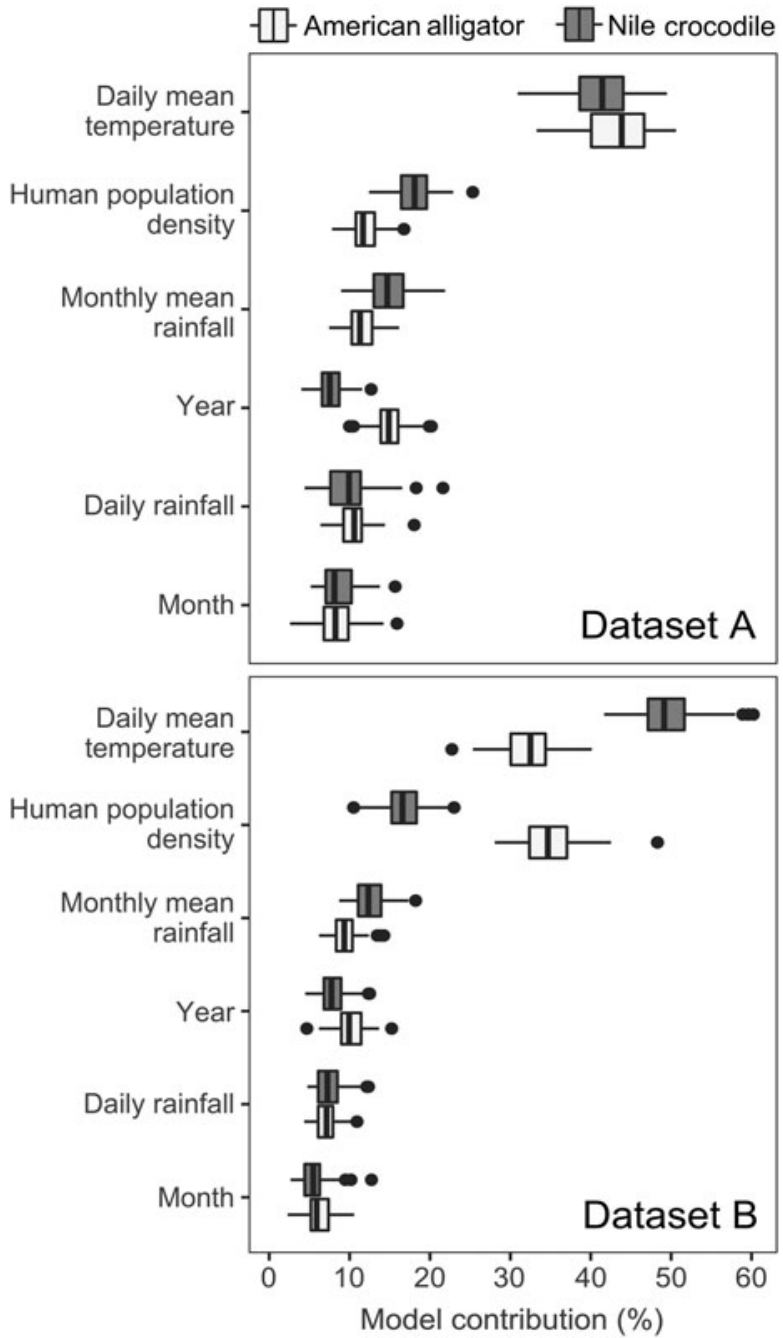

FIG. 4 Boxplots of variable contribution for boosted regression trees (BRTs) for Nile crocodile and American alligator attack occurrence. BRTs were fit 100 times with a ratio of 1:1 presence to background points sampled from two background datasets. Background dataset A contained background points sampled from attack locations over the study periods. Background dataset B contained background points sampled across the species' predicted ranges over the study periods.

in the model. These indicate that attack likelihood increases markedly when mean daily temperature exceeds $18^{\circ} \mathrm{C}$ for both species, and that it plateaus above c. $28^{\circ} \mathrm{C}$ (Fig. 5). This does not mean attacks could not occur at temperatures below $18{ }^{\circ} \mathrm{C}$. For example, the minimum daily average temperature linked to Nile crocodile and American alligator attacks in our dataset were $10.6{ }^{\circ} \mathrm{C}$ and $12.5^{\circ} \mathrm{C}$, respectively.

\section{Discussion}

Using environmental niche modelling, we explored the influence of abiotic and biotic environmental variables on crocodilian attack occurrence at a finer spatial and temporal resolution than in previous studies. Three key findings 

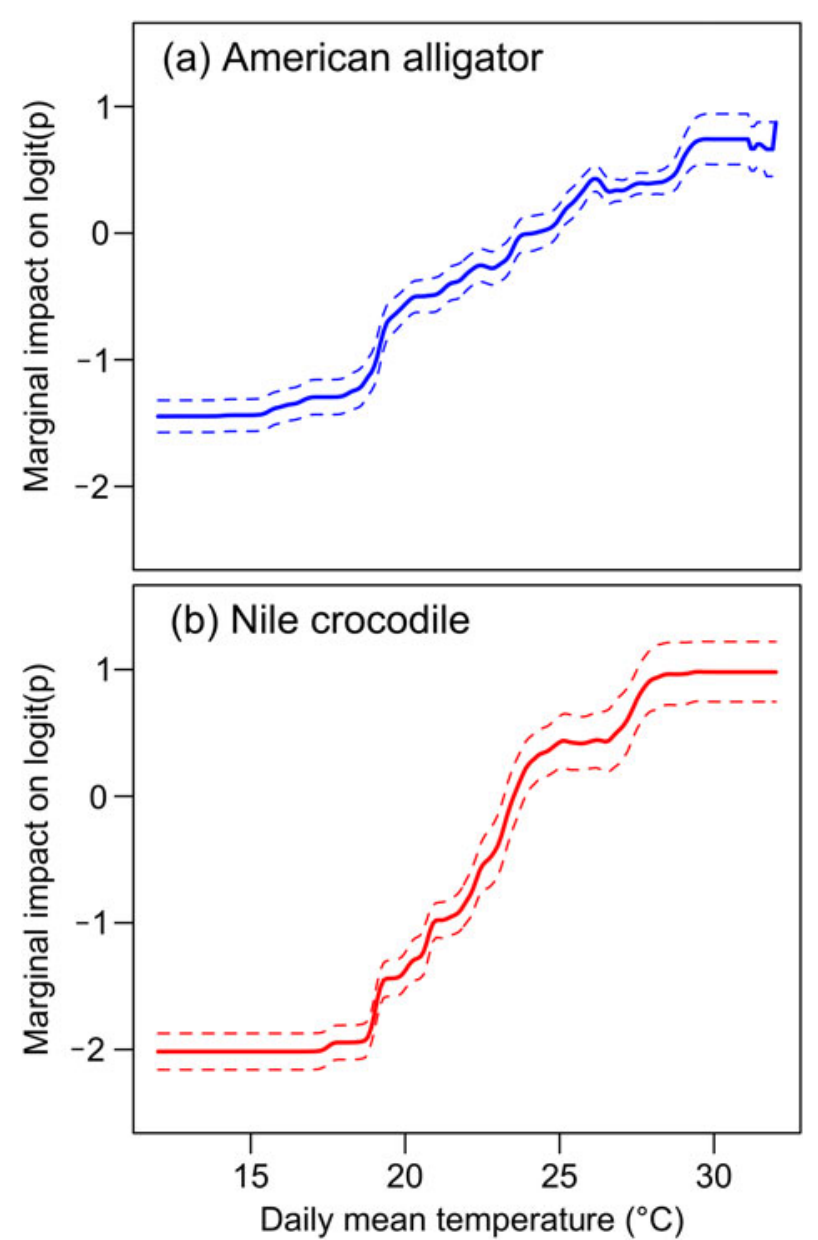

FIG. 5 Boosted regression tree (BRT) partial dependence plots showing the marginal impact of daily average temperature (x-axis) on attack likelihood (y-axis) for (a) American alligators and (b) Nile crocodiles after accounting for the average effects of all other variables in the model. The mean (solid lines) and standard errors (dashed lines) were calculated across all 100 model fitting iterations. Y-axes are on the logit scale and are centred to have zero mean over the data distribution.

emerged for both Nile crocodiles and American alligators. Firstly, temperature was the most important abiotic temporal predictor of attack occurrence. Secondly, attack likelihood increased markedly when mean daily temperature exceeded $18^{\circ} \mathrm{C}$. Thirdly, the probability of attacks was highest above $28^{\circ} \mathrm{C}$, where it plateaued. We discuss three non-mutually exclusive hypotheses that may explain these findings.

From the perspective of crocodilian behaviour, attack likelihood may increase with ambient temperature for physiological reasons. As ectotherms, the ability of crocodilians to digest food and to hunt is dependent on ambient temperatures (Hutton, 1987; Emshwiller \& Gleeson, 1997; Seebacher \& Franklin, 2005). For instance, in alligators, digestive efficiency increases significantly as body temperature rises from 25 to $31^{\circ} \mathrm{C}$ (Coulson \& Coulson, 1986), and they stop eating when ambient temperatures drop below $16^{\circ} \mathrm{C}$
(Lance, 2003). Hossain et al. (2013) found comparable patterns for captive saltwater crocodiles. In our study, a remarkably similar relationship was evident, including comparable minimum and maximum temperature thresholds, which offers strong support for the hypothesis that ambient temperature influences attack patterns via its effect on crocodilian physiology (Seebacher \& Franklin, 2005; Mazzotti et al., 2016).

A related hypothesis proposes that increased attacks at higher temperatures reflect heightened crocodilian aggression during the breeding season, mediated either by the effect of testosterone on male behaviour or female nest-guarding (Pooley et al., 1992). However, studies on alligators indicated that testosterone was not correlated with attack frequency (Woodward et al., 2014), and the limited research on hormones and breeding undertaken on captive Nile crocodiles suggests that heightened hormone levels and breeding occur during the late winter months, when attack occurrence is low (Kofron, 1990; J. Myburgh, pers. comm., 2018). Similarly, in the USA, limited data suggest elevated testosterone levels in the early breeding season (FebruaryMarch) that decline sharply over summer (Hamlin et al., 2011). Moreover, for Nile crocodiles, nest-guarding in most regions occurs in the hottest months, meaning many of the larger adult females are not hunting and remain on or near their nests, reducing the likelihood of attacks by these animals (Pooley et al., 1992; Kofron, 1990; Combrink et al., 2017).

From a human behavioural perspective, attack likelihood may increase with ambient temperature as a result of people spending more time in and around water in hot weather, increasing encounters with crocodilians. In South Africa and Eswatini, nearly half of all attacks occurred on weekends and holidays, suggesting that human activity patterns are important. In further support of this, data collected from our study area in southern Africa suggest that Nile crocodile attacks occur most often during activities such as crossing rivers, doing domestic chores, fishing and swimming (Pooley et al., 2019), and similar observations have been made in Zambia (Wallace et al., 2011). This hypothesis is clearly applicable to temperature-dependent activities, such as swimming, but is less so for river crossing and domestic chores, which occur year-round (although they may differ in duration and method at different temperatures). Unfortunately, because of the lack of direct data on human activity levels for the full duration of the study periods, we are currently unable to quantify how changes in human behaviour contribute to attack patterns. However, this highlights an important subject for future research.

Variable importance and predictive accuracy (measured as ROC) of the models were influenced by how background points were sampled. Predictive accuracy and the relative importance of human population density as a predictor were increased for the American alligator attack model when background points were sampled from across all 
counties in Florida (stratified by total wetland area), as opposed to stratified by counties in which attacks have occurred. This is probably a result of spatial variation in attack likelihood between counties, which is captured by human population density because of the close association between human population density and county. This is supported by the non-linear relationship observed between attack likelihood and human population density across Florida. Spatial variation in attack likelihood is probably a result of the patchy distribution of American alligators across their predicted range and resulting variation in human-crocodilian exposure rates.

Our findings have implications for crocodilian conservation. In particular, improving our understanding of the climatic conditions under which negative interactions between people and crocodilians are more common could inform future strategies for conflict management, including educating local communities in high-risk areas about the relationship between temperature and attack occurrence. Our findings could also discourage antagonistic approaches that threaten crocodilian welfare, such as removal, extermination and nest destruction (Woodward et al., 2014). Behavioural modification strategies are likely to be more practical for irregular activities that can be scheduled during the winter, such as dam repair (see CrocBITE, 2018, for reports of attacks on divers). However, the use of crocodilian-inhabited waterways for domestic chores and livelihoods could also be modified by organizing essential activities during cooler periods. As with all conflict mitigation strategies, this comes with the caveat that attacks may still be possible at colder temperatures because of individual variation in crocodilian behaviour and physiology or the risk of accidental encounters (e.g. stumbling upon a nest or treading on a crocodilian). This is especially true when temperatures are relatively low at dawn, dusk or during the night, as crocodilian activity often increases during these periods and humans or other prey are more vulnerable to attack because of poor light conditions (CrocBITE, 2018). More generally, in regions with less seasonal temperature variation, the behavioural modification strategies described above may not be effective. For example, in India and Bangladesh, mean daily temperature rarely drops below $23^{\circ} \mathrm{C}$, which is within the physiological range at which crocodilians hunt (Das \& Jana, 2017).

Seasonal limitations on crocodilian attacks linked to temperature could be affected markedly by predicted trends in global warming. For instance, average temperatures in Africa are predicted to increase by as much as $5-8^{\circ} \mathrm{C}$ by 2050 (Ziervogel et al., 2014; Munzhedzi, 2018). This is likely to facilitate more regular hunting by crocodiles, potentially to the point that it becomes commonplace throughout the year, as it is in equatorial Africa, India and Bangladesh. Ongoing monitoring of the influence of temperature changes on crocodilian behaviour and their effect on attack patterns will be important.
Our findings also have implications beyond crocodilian conflict management. The finding that crocodilian attack patterns appear to be influenced by inherent physiological constraints that are common to all ectotherms suggests that similar methods could be applied to understand negative interactions with other species. For example, snakes commonly bite humans, their pets and livestock, and the World Health Organization (2018) estimates that c. 5 million snakebites occur annually, resulting in $81,000-138$, 000 deaths. This issue has been neglected, resulting in the slow development of mitigation strategies (Mohapatra et al., 2011). However, as with crocodilians, there is both theoretical and observational evidence that behaviour in snakes is influenced by climatic factors, including temperature constraints on metabolism (Saint Girons, 1980; Wang et al., 2002). Seasonal snakebite patterns peak in the summer months in Bangladesh (Rahman et al., 2010) and Nepal (Longkumer et al., 2017). Our methods could also be applied to local issues that affect small communities, such as attacks by Komodo dragons on people, pets and livestock in Indonesia. These attacks were reported to have affected $33.3 \%$ of people in a study of affected areas (Ardiantiono et al., 2015).

In addition, the current approach of linking attacks by endothermic predators to spatial variables such as topography and urban land use (Zarco-González et al., 2013; Behdarvand et al., 2014; Kabir et al., 2014; Carvalho et al., 2015) could be expanded to include abiotic predictors. The heat dissipation hypothesis suggests that activity in large species, including dangerous predators such as the tiger Panthera tigris tigris, leopard Panthera pardus saxicolor, lion Panthera leo and hunting dog Lycaon pictus, will be limited during hotter periods because of the difficulty of thermoregulating (Acharya et al., 2016; Smith \& Kok, 2006; Creel et al., 2016; Ghoddousi et al., 2016; Robertson et al., 2019). A recent study exploring injuries and fatalities caused by large mammals in Nepal found that attacks on humans by elephants Elephas maximus, rhinoceroses Rhinoceros unicornis and tigers were all significantly higher in the winter, potentially indicating increased aggression among both predators and large herbivores at colder temperatures when vigorous activity becomes less problematic (Acharya et al., 2016). As with previous work on crocodilians, Acharya et al. used monthly climatic data that only offered a coarse temporal resolution. Our methods, therefore, could provide a template for the study of human-endotherm conflict.

In conclusion, our findings offer strong support for the hypothesis that seasonality of crocodilian attacks is determined predominantly by temperature in regions where fluctuations are large enough to have significant impacts on crocodilian behaviour. We provide the first evidence of this at a high spatial and temporal resolution. Our analysis demonstrates that attacks increase predictably across a given temperature range and appear to be constrained by 
a biologically-relevant threshold. This has the potential to inform conflict management and conservation. The strong theoretical grounding for the temperature-physiology relationship suggests that our approach could be of value in casting light on the dynamics of conflict between people and other species, including both ectotherms and endotherms.

Acknowledgements We thank Allan Woodward and the Florida Fish \& Wildlife Conservation Commission for alligator attack data. Prior to this study, SP worked on early ideas on the seasonality of crocodile attacks related to biophysical variables with Joshua Potter and Aiden Keane.

Author contributions Conception: SP, GP; data collection: SP; environmental and spatial data collection, data preparation: GP, JJW; analyses: GP, ST; writing: TMMV, GP; revisions: all authors.

\section{Conflicts of interest None.}

Ethical standards This research abided by the Oryx guidelines on ethical standards, and did not involve human or animal test subjects or the collection of specimens.

\section{References}

Acharya, K., Paudel, P., Neupane, P. \& Köhl, M. (2016) Humanwildlife conflicts in Nepal: patterns of human fatalities and injuries caused by large mammals. PLOS ONE, 11, eo161717.

Ardiantiono, A., Imansyah, M. \& Andayani, N. (2015) Understanding Human-Komodo Dragon Conflict in Komodo Village, Komodo National Park, with Suggestions for Conflict Mitigation and Prevention. The 1st Symposium on South East Asia Herpetology and Envenomation, Malang, Indonesia.

Aust, P., Boyle, B., Fergusson, R. \& Coulson, T. (2009) The impact of Nile crocodiles on rural livelihoods in northeastern Namibia. South African Journal of Wildlife, 39, 57-69.

Barbet-Massin, M., Jiguet, F., Albert, C.H. \& Thuiller, W. (2012) Selecting pseudo-absences for species distribution models: how, where and how many? Methods in Ecology and Evolution, 3, 327-338.

Behdarvand, N., Kaboli, M., Ahmadi, M., Nourani, E., Salman Mahini, A. \& Asadi Aghbolaghi, M. (2014) Spatial risk model and mitigation implications for wolf-human conflict in a highly modified agroecosystem in western Iran. Biological Conservation, $177,156-164$.

Beisner, B.A., Heagerty, A., Seil, S.K., Balasubramaniam, K.N., Atwill, E.R., Gupta, B.K. et al. (2015) Human-wildlife conflict: proximate predictors of aggression between humans and rhesus macaques in India. American Journal of Physical Anthropology, 156, 286-294.

Brien, M.L., Gienger, C.M., Browne, C.A., Read, M.A., Joyce, M.J. \& Sullivan, S. (2017) Patterns of human-crocodile conflict in Queensland: a review of historical estuarine crocodile (Crocodylus porosus) management. Wildlife Research, 44, 281-29o.

Britton (2009) Crocodilian Species List. crocodilian.com/cnhc/csp_ amis.htm [accessed 21 May 2019].

Carvalho, E.A.R., Zarco-González, M.M., Monroy-Vilchis, O. \& Morato, R.G. (2015) Modeling the risk of livestock depredation by jaguar along the Transamazon highway, Brazil. Basic and Applied Ecology, 16, 413-419.

Combrink, X., Jonathan, K., Warner, C. \& Downs, C.T. (2017) Nest-site selection, nesting behaviour and spatial ecology of female
Nile crocodiles (Crocodylus niloticus) in South Africa. Behavioural Processes, 135, 101-112.

Coulson, R.A. \& Coulson, T.D. (1986) Effect of temperature on the rates of digestion, amino acid absorption and assimilation in the alligator. Comparative Biochemistry and Physiology Part A Physiology, 83, 585-588.

Creel, S., Creel, N.M., Creel, A.M. \& Creel, B.M. (2016) Hunting on a hot day: effects of temperature on interactions between African wild dogs and their prey. Ecology, 97, 2910-2916.

CrocBITE (2018) The Worldwide Crocodilian Attack Database. crocodile-attack.info [accessed 1 August 2018].

DAs, C.S. \& JANA, R. (2017) Human-crocodile conflict in the Indian Sundarban: an analysis of spatio-temporal incidences in relation to people's livelihood. Oryx, 52, 661-668.

Defence Mapping Agency (1992) Digital Chart of the World. Defence Mapping Agency, Fairfax, USA.

Dunham, K.M., Ghiurghi, A., Cumbi, R. \& Urbano, F. (2010) Human-wildlife conflict in Mozambique: a national perspective, with emphasis on wildlife attacks on humans. Oryx, 44, 185-193.

Elith, J., Graham, C.H., Anderson, R.P., Dudík, M., Ferrier, S., Guisan, A. et al. (2006) Novel methods improve prediction of species' distributions from occurrence data. Ecography, 29, 129-151.

Elith, J., Leathwick, J.R. \& Hastie, T. (2008) A working guide to boosted regression trees. Journal of Animal Ecology, 7, 802-813.

Emshwiller, M. \& Gleeson, T. (1997) Temperature effects on aerobic metabolism and terrestrial locomotion in American alligators. Journal of Herpetology, 31, 142-147.

Fick, S.E. \& HiJmans, R.J. (2017) Worldclim 2: new 1-km spatial resolution climate surfaces for global land areas. International Journal of Climatology, 37, 4302-4315.

Friedman, J.H. \& Meulman, J.J. (2003) Multiple additive regression trees with application in epidemiology. Statistics in Medicine, 22, 1365-1381.

Fukuda, Y., Manolis, C., Saalfeld, K. \& Zuur, A. (2015) Dead or alive? Factors affecting the survival of victims during attacks by saltwater crocodiles (Crocodylus porosus) in Australia. PLOS ONE, 10, e0126778.

FWC (2016) Florida Alligator Bite Data. Courtesy of Dr Allan Woodward, Florida Fish \& Wildlife Conservation Commission, Tallahassee, USA.

Ghoddousi, A., Soofi, M., Kh Hamidi, A., Lumetsberger, T., Egli, L., Khorozyan, I. et al. (2016) Assessing the role of livestock in big cat prey choice using spatiotemporal availability patterns. PLOS ONE, 11, e0153439.

Giraut, F. \& Vacchiani-Marcuzzo, C. (2009) Territories and Urbanisation in South Africa: Atlas and Geo-Historical Information System (DYSTURB). Institut de Recherche pour le Développement, Marseille, France.

Hamlin, H.J., Lowers, R.H. \& Gillette, JR, L.J. (2011) Seasonal androgen cycles in adult male American alligators (Alligator mississippiensis) from a Barrier Island Population. Biology of Reproductions, 85, 1108-1113.

Hossain, M.S., Jaman, M.F., Ahmed, M., Rahman, M.M. \& Uddin, M. (2013) Food consumption of saltwater crocodile (Crocodylus porosus) in a reptile farm of Bangladesh. Bangladesh Journal of Zoology, 41, 173.

Hutton, J. (1987) Growth and feeding ecology of the nile crocodile Crocodylus niloticus at Ngezi, Zimbabwe. Journal of Animal Ecology, 56, 25-38.

iCAO (International Civil Aviation Organization) (2017) International Standard Atmosphere. ivao.aero/training/ documentation/books/Student_ISA.pdf [accessed 2 May 2017].

IUCN (1996) Crocodylus niloticus. In The IUCN Red List of Threatened Species 2019: e.T45433088A3010181. iucnredlist.org/species/46590/ 11064465 [accessed 2 May 2017]. 
Kabir, M., Ghoddousi, A., Awan, M.S. \& Awan, M.N. (2014) Assessment of human-leopard conflict in Machiara National Park, Azad Jammu and Kashmir, Pakistan. European Journal of Wildlife Research 60, 291-296.

Kofron, C.P. (1990) The reproductive cycle of the Nile crocodile (Crocodylus nilotkus). Journal of Zoology, 221, 477-488.

Lamarque, F., Anderson, J., Fergusson, R.A., Lagrange, M., Osei-Owusu, Y. \& BAKker, L. (2009) Human-wildlife Conflict in Africa: Causes, Consequences and Management Strategies. FAO, Rome, Italy.

LANCE, V.A. (2003) Alligator physiology and life history: the importance of temperature. Experimental Gerontology, 38, 801-805.

Longkumer, T., Armstrong, L.J. \& Finny, P. (2017) Outcome determinants of snakebites in North Bihar, India: a prospective hospital-based study. Journal of Venom Research, 8, 14-18.

Mazzotti, F.J., Cherkiss, M.S., Parry, M., Beauchamp, J., Rochford, M., Smith, B. et al. (2016) Large reptiles and cold temperatures: do extreme cold spells set distributional limits for tropical reptiles in Florida? Ecosphere, 7, eo1439.

Miller, J.R.B. (2015) Mapping attack hotspots to mitigate humancarnivore conflict: approaches and applications of spatial predation risk modelling. Biodiversity Conservation, 24, 2887-2911.

Mohapatra, B., Warrell, D.A., Suraweera, W., Bhatia, P., Dhingra, N., JotKar, R.M. et al. (2011) Snakebite mortality in India: a nationally representative mortality survey. PLOS Neglected Tropical Diseases, 5, e1018.

Munzhedzi, S. (2018) Climate Trends and Scenarios, Climate and Impacts Factsheet Series, Factsheet 2 of 7 . Department of Environmental Affairs, Climate Change Branch, Pretoria, South Africa. sanbi.org/ wp-content/uploads/2018/03/ltas-factsheetclimate-trends-andscenarios2013.pdf [accessed 20 February 2019].

OedR (Office of Economic \& Demographic Research) (2017) Population \& Demographics. edr.state.fl.us/content/populationdemographics/index.cfm [accessed 28 April 2017].

Phillips, S.J., Dudík, M., Elith, J., Graham, C.H., Lehmann, A., Leathwick, J. \& Ferrier, S. (2009) Sample selection bias and presence-only distribution models: implications for background and pseudo-absence data. Ecological Applications, 19, 181-197.

Pooley, A.C., Hines, T. \& Shield, J. (1992) Attacks on humans. In Crocodiles and Alligators (ed. C.A. Ross), 2nd edition, pp. 172-187. Merehurst, London, UK.

Pooley, S. (2015) Using predator attack data to save lives, human and crocodilian. Oryx, 49, 581-583.

Pooley, S., Botha, H., Combrink, X. \& Powell, G. (2019) Synthesising Nile crocodile attack data and historical context to inform mitigation efforts in South Africa and eSwatini (Swaziland). Oryx, published online 11 July 2019.

R Core Team (2018) The R Project for Statistical Computing. r-project. org [accessed January 2018].

Rahman, R, Faiz, M.A., Selim, S., Rahman, B., Basher, A., Jones, A. et al. (2010) Annual incidence of snake bite in rural Bangladesh. PLOS Neglected Tropical Diseases, 4, e86o.
Ridgeway, G. (2010) gbm: Generalized Boosted Regression Models: $R$ Package Version 1.6-3.1. CRAN.R-project.org/package $=$ gbm [accessed 20 March 2017].

Robertson, J.A.D., Roodbol, M., Bowles, M.D., Dures, S.G. \& RowCliffe, J.M. (2019) Environmental predictors of livestock predation: a lion's tale. Oryx, published online 7 June 2019.

Saint Girons, H. (1980) Thermoregulation in reptiles with special reference to the tuatara and its ecophysiology. Tuatara, 24, 59-80.

Seebacher, F. \& Franklin, C.E. (2005) Physiological mechanisms of thermoregulation in reptiles: a review. Journal of Comparative Physiology B: Biochemical, Systemic, and Environmental Physiology, $175,533-541$.

Sмiтh, Y. \& Kок, O.B. (2006) A suggested thermoneutral zone for African lions (Panthera leo Linnaeus, 1758) in the Southwestern Kalahari, Namibia. Pakistan Journal of Biological Sciences, 9, 2535-2537.

UN (United Nations) (2017) World Population Prospects: The 2017 Revision. un.org/development/desa/publications/world-populationprospects-the-2017-revision.html [accessed 10 December 2018].

U.S. Fish \& Wildlife Service (2017) National Wetlands Inventory-Version 2-Surface Waters and Wetlands Inventory. U.S. Fish \& Wildlife Service, Washington, DC, USA.

van der Ploeg, J., Cauillan-Cureg, M., van Weerd, M. \& Persoon, G. (2011) 'Why must we protect crocodiles?' Explaining the value of the Philippine crocodile to rural communities. Journal of Integrative Environmental Sciences, $8,287-298$.

Wallace, K.M., Leslie, A. \& Coulson, T. (2011) Living with predators: a focus on the issues of human-crocodile conflict within the lower Zambezi valley. Wildlife Research, 38, 747-755.

Wang, T., ZaAr, M., Arvedsen, S., Vedel-Smith, C. \& OvergaARD, J. (2002) Effects of temperature on the metabolic response to feeding in Python molurus. Comparative Biochemistry \& Physiology. Part A: Molecular and Integrative Physiology, 133, 519-527.

Woodroffe, R., Thirgood, S. \& Rabinowitz, A. (eds) (2005) People and Wildlife, Conflict or Co-Existence? (Conservation Biology). Cambridge University Press, Cambridge, UK.

Woodward, A.R., Leone, E.H., Dutton, H.J., Hord, L. \& Waller, J.E. (2014) Human alligator conflict in Florida, USA. In Crocodiles. Proceedings of the 23rd Working Meeting of the IUCN-SSC Crocodile Specialist Group, 182-199. IUCN, Gland, Switzerland.

WhO (World Health Organization) (2018) Snakebite envenoming. who.int/snakebites/disease/en [accessed 1 August 2018].

Young, A.H., Knapp, K.R., Inamdar, A., Rossow, W.B. \& Hankins, W. (2017) The International Satellite Cloud Climatology Project H-Series climate data record product. Earth System Science Data, 10, 583-593.

Zarco-González, M.M., Monroy-Vilchis, O. \& Alaníz, J. (2013) Spatial model of livestock predation by jaguar and puma in Mexico: conservation planning. Biological Conservation, 159, 80-87.

Ziervogel, G., New, M., Archer van Garderen, E., Midgley, G., TAYlor, A., Hamann, S. et al. (2014) Climate change impacts and adaptation in South Africa. WIREs Climate Change, 5, 605-620. 